\title{
POLÍTICAS DO CUIDADO: INTERFACES CONTEMPORÂNEAS ENTRE SAÚDE E FAMÍlIA
}

\author{
DÉBORA AlLEBRANDT ${ }^{1}$ e WALESKa Aureliano ${ }^{2}$
}

Os estudos de família e parentesco foram durante muito tempo centrais para o desenvolvimento da antropologia. Da clássica obra de Lewis Morgan (1870) que inspirou Marx e Engels em suas análises sobre o origem da família, da propriedade e do Estado, passando pelos diagramas de parentesco de Rivers (1969) e a análise estruturalista de Lévi-Strauss(1982), para citar apenas alguns autores, a temática se confundiu até certo momento com o desenvolvimento teóricometodológico da disciplina. Entretanto, posicionamentos críticos emergiram a partir dos anos 1970, sobretudo, com o trabalho de David Schneider (1984), arrefecendo o interesse pelo tema. Schneider e outros membros da chamada antropologia simbólica sugeriram que os termos analíticos utilizados para definir família e parentesco refletiam nada mais do que os valores da sociedade dos pesquisadores, nas quais essas categorias são significadas, principalmente, através de uma noção biológica do vínculo, centrada na consanguinidade ${ }^{3}$.

É apenas a partir dos anos 1990 que ocorre uma "retomada" do tema "família e parentesco" fomentada pelos estudos das sociedades complexas e em relação com as áreas da saúde, das tecnologias reprodutivas e dos estudos feministas (FONSECA, 2003, 2007). Neste cenário, muitas pesquisas se detiveram sobre biotecnologias utilizadas, principalmente, nas escolhas reprodutivas contemporâneas que estão informadas por novos arranjos familiares presentes nas sociedades modernas e balizados por diferentes questões: da reivindicação de autonomia das mulheres para o exercício de uma "maternidade independente" à judicialização da paternidade com os testes de DNA; da construção de famílias homoparentais à transformação do "problema em ter filhos" em "problema médico" capaz de ser solucionado com a tecnologia biomédica (FONSECA, 2003, 2007). Família e parentesco ressurgem, assim, como categorias marcadas fortemente pelo

\footnotetext{
1 Professora do Programa de Pós-Graduação em Antropologia Social da Universidade Federal de Alagoas. Contato: debora.allebrandt@ics.ufal.br

${ }^{2}$ Professora Adjunta da Universidade do Estado do Rio de Janeiro. Contato: waurelianorio@gmail.com

${ }^{3}$ Embora haja uma larga discussão na antropologia que defende a separação analítica entre os conceitos de "família" e "parentesco", adotamos aqui o uso dos termos como intercambiáveis, tal como apresentado no argumento de Claudia Fonseca em seu artigo neste dossiê, por entender que ambos estão intrinsecamente relacionados às práticas do cuidado.
} 
direito e pela medicina, ambos interconectados nos processos de definição e construção desses conceitos e informados por biotecnologias.

No entanto, a relação entre família-parentesco e saúde-direito não é recente. Michel Foucault (2000) analisou em sua obra a emergência, entre os séculos XVIII e XIX, do lugar central da família nos cuidados com a saúde e em estreita relação com a construção do saber médico. Ao observar a formação do que chamamos medicina social, Foucault analisou como se deu a trajetória de disciplinarização da medicina como saber científico a partir de sua atuação política na formação dos Estados europeus (sobretudo o alemão), no exercício de uma medicina urbana que tratasse dos problemas gerados pela crescente urbanização das cidades (analisando o caso da França) e a medicalização dos pobres, utilizada como instrumento de controle das classes trabalhadoras (o caso da Inglaterra). Era uma medicina que se dispunha a cuidar dos indivíduos através de uma atuação assistencialista destinada aos pobres, e da população através do controle das epidemias, da vacinação e higienização das cidades. Aquele que seria o representante maior da medicina - o médico - foi investido de poderes para gerir e deliberar não apenas sobre a saúde dos indivíduos, mas sobre a forma como eles se organizavam e viviam socialmente, sobre seus direitos e deveres, instituindo uma "série de prescrições que dizem respeito não só à doença mas às formas gerais da existência e do comportamento (a alimentação e a bebida, a sexualidade e a fecundidade, a maneira de se vestir, a disposição ideal do habitat)" (FOUCAULT, 2000, p. 202)

Naquele contexto de crescente medicalização da vida, modelos de organização familiar foram projetados com objetivo de garantir a saúde de seus membros e, consequentemente, da sociedade e da nação. Além de propor o controle da periculosidade sanitária (higienização das cidades) e o saneamento dos espaços públicos, o saber médico também atuou na ordenação da vida familiar. Para concretização desse ordenamento, a mulher foi chamada a cumprir um papel que, segundo a medicina do século XIX, estaria de acordo com a sua "natureza". A mulher passou a ser valorizada como esposa e mãe e adquiriu maior poder de atuação dentro do lar, no espaço privado, a partir do momento em que foi colocada para ela a atribuição do cuidado dos filhos e a administração do espaço doméstico (ver também DONZELOT, 1986). Ela se tornou a primeira e mais importante aliada da medicina na execução dos controles relacionados à manutenção da saúde nos lares, sobretudo nas ações que diziam respeito ao controle da mortalidade infantil. A partir da construção da figura moral da mãe-mulher com cuidadora "natural", responsável pelo bem-estar da família, as políticas de proteção social familistas que surgiram no século XX mostram-se herdeiras dessa caracterização. Seja em contextos liberais, neoliberais "humanizados" ou progressistas, a família constituiu-se como categoria consensual, e a mulher como responsável por sua saúde.

O final do século XX e início do século XXI foi marcado por uma série de eventos que continuaram a demandar formulações sobre o lugar da família nos processos de saúde e doença: da 
epidemia do HIV/Aids ao Projeto Genoma Humano, da fertilização in vitro a novas perspectivas em torno da gestação e do parto, da reforma psiquiátrica a doação de órgãos. Em todos esses eventos a família foi constantemente acionada seja como lugar de cuidado, de origem de um "problema" (para as doenças genéticas hereditárias) ou como agente na construção de políticas públicas em saúde.

No que tange o crescente uso de biotecnologias tanto para reprodução como para diagnóstico e tratamentos de algumas doenças, Kaja Finkler (2001) propõe que, contemporaneamente, as categorias família e parentesco teriam sido medicalizadas com o advento da nova genética. Para a autora, que desenvolveu suas pesquisas nos Estados Unidos, a medicina genética estaria definindo família em termos tradicionais baseados no sangue e nos genes na contramão das transformações contemporâneas pelas quais o conceito de família tem passado nas sociedades modernas nas quais a escolha individual e a autonomia dos sujeitos com relação à família tem se constituído em um valor. Haveria na medicina genética a atribuição de um significado cultural dado à transmissão genética que reflete, segundo a autora, a percepção americana do parentesco como algo biogenético, conforme já analisado em Schneider (1984), reforçando o padrão tradicional da família ocidental. Este fato produziria, segundo Finkler (2001), tensões entre a noção de autonomia individual em relação à família, largamente difundida nas sociedades modernas capitalistas nas quais a família passa a ser pensada em termos de escolhas individuais e afetivas, e conceituações tradicionalistas de família onde os laços familiares seriam determinados biologicamente. A autora realizou pesquisa com pessoas saudáveis de famílias com histórico de doenças crônico-degenerativas e câncer e também com pessoas adotadas. Nos dois grupos a autora observou a adoção de práticas de atenção e cuidado motivadas pela noção do "risco genético" entre pessoas que eram completamente saudáveis: do uso regular de exames no monitoramento de possíveis doenças e escolhas quanto à gestação de filhos, a busca pelos pais biológicos no intuito de construir um histórico clínico familiar a ser apresentado nos encontros médicos.

No entanto, apesar da grande consideração que se pode ter pela ideia de "herança", antes transmitida pelo sangue e agora centradas nos genes, outras autoras têm analisado como as dinâmicas da família e do parentesco no contemporâneo se tornaram complexas, sendo as próprias biotecnologias vetor de novas fabulações sobre as noções de vínculo e pertencimento, ora reforçando o aspecto biológico dessas ligações, ora relativizando-o (ver, entre outros ALLEBRANDT, 2015; BESTARD, 2012; MARRE; BESTARD, 2012; SILVERMAN, 2008). Tais tecnologias colocaram em questão a dimensão biológica da definição de família e parentesco ao apontar para formas de reprodução nas quais seria possível haver uma "confusão" dos lugares tradicionalmente ocupados por pais, mães e filhos na nossa sociedade. Ao mesmo tempo elas podem contribuir para definições medicalizadas de família e parentesco, especialmente através da genética e de pesquisas sobre doenças crônico-degenerativas (cf. FINKLER, 2001). 
Afinando-se com esse percurso histórico e contemporâneo, este dossiê apresenta contribuições importantes para se pensar as interfaces entre família e saúde na atualidade. São sete artigos que nos trazem diferentes perspectivas para se pensar a construção da família e do parentesco através do campo da saúde e em complexas relações com o Estado, a justiça, a medicina, o direito e os marcadores sociais da diferença, especialmente aqueles ligados a gênero, classe e raça.

O artigo de Claudia Fonseca abre o dossiê problematizando a noção de pertencimento, como chave para o entendimento do parentesco contemporâneo a partir da análise etnográfica de narrativas das violações de direitos humanos de filhos e filhas de pessoas acometidas pela Hanseníase no Brasil. Para a autora, o pertencimento não seria resultado de uma rede de consanguíneos e afins, mas produto de relacionalidades influenciadas por contextos e circunstâncias de diferentes esferas (materiais, imateriais, humanos e não humanos).

Ao examinar os emaranhados fios do pertencimento dessas famílias, Fonseca aborda a construção da materialidade de elementos como documentos, lembranças e DNA. Aprofundando estes aspectos, a autora discute mais do que as dinâmicas de pertencimento, mas o modo como as materialidades desses elementos são agenciadas em circunstâncias específicas. Nesse caso, a possibilidade de reparação futura para os filhos que foram separados de seus pais através da internação compulsória de pacientes com hanseníase. Considerando profundas transformações sociais que envolvem a economia e tecnologia que encurtaram distâncias e possibilitaram trânsito desses sujeitos, eventos críticos, tecnologia e circunstancialidade são tomadas como co-construtoras da materialização e vivência de laços de pertencimento.

Na sequência, Romario Nelvo desenvolve em seu artigo uma análise sobre as "dores que vazam" no cotidiano do cuidado, ao mostrar como a burocracia estatal atravessa a busca de uma mãe por tratamento para seu filho, se refletindo também em seu próprio corpo e sua casa. Articulando os marcadores de classe, raça e gênero, Nelvo apresenta seu percurso de pesquisa ao lado de Gal, mulher negra, moradora de uma comunidade em constante ameaça de remoção no Rio de Janeiro e mãe de um adulto de 33 anos que faz uso da maconha medicinal. 0 autor narra a peregrinação de Gal pela Defensoria Pública e outros órgãos estatais em busca do dinheiro que possibilitará a compra do medicamento que seu filho necessita utilizar para conter as convulsões causadas por uma doença rara. Nesse longo trajeto de idas e vindas, esperas e frustrações, Gal nos fala da sua casa que está desarrumada porque ela precisa estar na Defensoria várias vezes por semana para que os agentes do Estado não pensem que ela desistiu da sua demanda. Nos fala também de seus "problemas de vista" e hipertensão que não podem ser resolvidos porque não há tempo para mais nada a não ser a luta cotidiana dentro dos corredores dos órgãos públicos.

Nelvo traz para o centro do debate sobre o ativismo pela maconha medicinal questões pouco exploradas, como as gramáticas morais de gênero e maternidade atravessadas pelas 
desigualdades de classe e raça. Chama nossa atenção também para o modo como o tempo da luta (ativismo) se conecta com o tempo da vida familiar (a casa desarrumada, as doenças da própria mãe que não são cuidadas) para nos falar do modo como as práticas do cuidado, que se expressam em espaços público e privado, são claramente generificadas porque recai majoritariamente sobre as mulheres seu exercício. Nos casos em que esse cuidado exige medicamentos demandados judicialmente e mobilização social para seu acesso, como no caso da maconha medicinal, caberá às mulheres dominar não apenas o ambiente doméstico, mas também a gramática estatal que concede ou anula as possibilidades do cuidar.

O domínio dessa gramática estatal também faz parte da análise de Victor Souza sobre a construção de uma política nacional para as doenças raras no Congresso Nacional. O autor acompanhou as audiências, reuniões e encontros entre parlamentares e ativistas/pacientes com doenças raras para a construção de um projeto de lei. Em seu artigo, Souza nos mostra como uma causa coletiva (a mobilização de pessoas com doenças raras) é transformada em pauta legislativa. Nesse processo, emergem uma série de padrões de responsabilidade e julgamentos ético-morais que são acionados pelos ativistas sobre o Estado, e vice-versa no momento em que as famílias e, principalmente, as mães, são identificadas pelos parlamentares como agentes essenciais para que a demanda das pessoas com doenças raras "ande" dentro do legislativo.

No entanto, da mesma forma que observado por Nelvo, o tempo da burocracia estatal difere do tempo da vida. Para sincronizar esse tempo pacientes e familiares buscam mobilizar emoções e moralidades no espaço político usando a gramática dos afetos na construção de leis. Por sua vez, os agentes do Estado exigem que essas emoções sejam expressas de determinada forma, atendendo ao "decoro" da ação política pública e em consonância com um modelo pré-estabelecido que rege as dinâmicas do Congresso. Para construção de uma lei, espera-se dos agentes sociais sintetizem o sofrimento em documentos propositivos, uma ordenação pragmática das aflições que possa ser inteligível ao poder público através do que o autor chama de as "expressões obrigatórias dos regimentos" numa associação com o argumento de Marcel Mauss em seu texto "A expressão obrigatória dos sentimentos" (2001). Não se pode simplesmente afirmar o óbvio sofrimento de quem tem uma doença rara degenerativa e debilitante, é preciso ordenar essa experiência para comunica-la com efetividade no âmbito político da produção de leis.

A tradução do artigo de Sahra Gibbon no traz a análise do processo de construção de uma área voltada para genética médica em Cuba tendo por base uma investigação sobre o câncer de mama hereditário. $\mathrm{O}$ artigo é baseado em pesquisa realizada com mulheres cubanas e profissionais da genética explorando o contexto social e cultural das crenças em saúde sobre o câncer de mama. Considerando o regime político-econômico que vigora no país desde o final dos anos 1950, a medicina cubana se desenvolveu com foco na prevenção e centrada no médico de família. Isso teria 
favorecido a emergência, no contemporâneo, de uma genética que se identifica como "comunitária".

A autora argumenta que as noções do "risco genético" vinculadas ao câncer de mama devem ser examinadas em relação às práticas institucionais dos serviços públicos de saúde em Cuba, que tem na família o seu foco. Ao mesmo tempo, a autora observa que concepções nativas de risco relacionadas ao surgimento do câncer de mama, como uma "pancada" nos seios, a disjunção realizada pelas mulheres entre o que seria um fator hereditário e um fator genético conhecido, e os tabus que ainda impedem a discussão aberta do diagnóstico de câncer na família produzem muitos desafios para a tradução e aplicação de intervenções da genética preditiva em Cuba. Haveriam continuidades e descontinuidades na maneira como as intervenções genômicas ligadas ao câncer de mama estão se desenvolvendo em Cuba, que dizem respeito ao modo como o câncer de mama é significado nesse contexto e como o sistema de saúde, de forma geral, se articula em torno da família que, de forma geral, é o 'sujeito' a ser investigado nos encontros médicos.

Seguindo a discussão de genética, saúde e família, o texto de Moraes, Ribeiro e Castiel explora a vivência e o diagnóstico da trombofilia a partir de uma reflexão auto-etnográfica. Abordando a dificuldade de diagnóstico por conta da dispendiosa testagem genética, as autoras abordam a noção de risco na saúde e o cálculo que se faz acerca de benefícios e perigos de cada tratamento. Há uma crítica sobre o modo como certos problemas de saúde são entendidos como graves e a suposta negligência com a saúde da mulher na prescrição indiscriminada de contraceptivos hormonais.

Nesse artigo a relação entre trombofilia e ausência involuntária de filhos (INHORN; BALEN, 2002; LEONARD, 2002) é abordada pelos custos dos tratamentos de reprodução assistida e pelos impactos da decisão de não ter filhos diante de tais circunstâncias. As consequências dessa decisão são problematizadas a partir de uma discussão de gênero que questiona imposições sociais que associam ser mulher com ser mãe e silenciam os riscos e os dilemas de mulheres que vivem com essa condição.

A interface entre gênero, saúde e família também é explorada por Neves que discute a medicalização das práticas de parto em quilombos do Recôncavo Bahiano. Diante da transformação do atendimento obstétrico no Brasil nos últimos 30 anos, esse artigo se ocupa do processo de transformação no padrão de assistência ao parto em comunidades tradicionais.

Aqui parto e nascimento são eventos políticos que marcam e permitem refletir sobre distintas concepções de saúde, corpo, identidade e vida comunitária. No contexto dos quilombos estamos falando de dinâmicas sociais e processos históricos em que há eventos envolvendo disputas entre corpos e territórios. A abordagem etnográfica da autora permite situar tradição como um processo histórico em que se inserem as parteiras após a influência da medicalização do parto e do 
nascimento. As narrativas trazidas nos levam a acreditar que a medicalização do parto levou a atuação das parteiras tradicionais para a clandestinidade e/ou atuação em casos de "necessidade" devido a processos de criminalização e perseguição que faziam eco aos processos de disputas territoriais e identitários. Neves destaca também o modo como as mulheres quilombolas não tem acesso a serviços de saúde e quando são atendidas em hospitais da região sofrem violências étnicas e de gênero. Nesse sentido a autora afirma que a gramática da violência toma lugar da gramática do cuidado.

Se debruçando sobre o problema do cuidado que o texto de Longhi nos conduz a dilemas em que saúde, cuidado, Estado e família estão em tensão. A autora nos lembra que tradicionalmente, cuidados com crianças e idosos sempre foram responsabilidade da "família". Essa responsabilidade atribuída a família, por sua vez, continua centrado nas mãos das mulheres que apesar de conquistarem novos espaços permanecem sendo as responsáveis por esses cuidados. Diante da polissemia do termo cuidado, a autora destaca que ele pode ser pensado como prática e como moral.

Longhi questiona a divisão dos cuidados entre Estado, Família e Mercado, problematizando o lugar do Estado e o cuidado como demanda política. Por outro lado, o entendimento bastante difundido que associa cuidado a afeto parece nos distanciar da consolidação dessa demanda. Segundo a autora, o cuidado (principalmente os dirigidos às pessoas idosas), visto a partir da lógica do afeto o associa a algo que deve ser merecido e não à um direito a ser garantido pelo Estado, aproximando substancialmente o cuidado do domínio privado e o afastando das políticas públicas.

Esse panorama de trabalhos que abordam a interface entre a saúde e a família nos colocam diante da centralidade do Estado nesse debate. No texto de Fonseca é o Estado que viola direitos humanos na criação de uma política de saúde que separava famílias tentando conter a proliferação de uma doença. É esse mesmo Estado que é cobrado anos depois e, dessa vez, sua negligência para com os registros dessa primeira política de saúde deixa encurraladas pessoas em busca de reparação.

O texto de Nelvo também aborda as violências (simbólica e física) perpetradas pelo Estado na vida de Gal, ao nos mostrar desde a ameaça recorrente de remoção de sua comunidade até a dificuldade de acesso a medicamentos, eventos cumulativos que agravam o sofrimento de sua família, afetada por uma doença rara. Para justificar sua ausência ou recusa em prover o que seria "de direito" dos cidadãos (saúde, moradia), o Estado, através dos seus agentes, também se considera "doente": estaria em crise, falido. Por sua vez, o texto de Souza nos mostra um Estado que é chamado a assumir uma causa coletiva como pauta legislativa, mas que para isso exige dos atores a conformação do sofrimento em uma linguagem de ordenamentos regimentais que possam ser convincentes para se produzir a desejada atenção esperada por familiares e pacientes com doenças 
raras, que aguardam há anos por uma política pública efetiva. São dois exemplos do Estado que produz leis e ao mesmo tempo não as cumpre.

No texto de Gibbon nos aproximamos da atuação do Estado cubano, com uma política pública de saúde integral que é tomada como exemplo em todo mundo. Ainda diante desse caso exemplar, a implementação da genética comunitária e estratégias de medicina genética preditiva encontram impasses e imprevistos. Nesse texto o Estado se apresenta como ente regulador e fonte de políticas públicas.

Moraes, Ribeiro e Castiel retratam mais um caso em que saúde, direitos reprodutivos e família são cerceados pela tácita relação entre Estado, medicina e mercado. Ora, como enfrentar a trombofilia e sua relação com a saúde das mulheres como uma questão grave sem criar um debate mais amplo sobre direitos reprodutivos para a contracepção e acesso à reprodução assistida? A ausência de diagnósticos de trombofilia, associada aos riscos do uso inadvertido de contraceptivos hormonais num cenário no qual não há interesse do Estado em desenvolver políticas preventivas acaba criando um cenário de estratificação da reprodução, no qual algumas mulheres tem acesso a informações e recursos que lhes permitem ter filhos e tê-los sob cuidado e melhores condições de saúde e outras não (LEONARD, 2002).

Nesse mesmo sentido, o texto de Neves revela as implicações políticas de transformação do atendimento obstétrico no Brasil. A ênfase na medicalização e patologização de eventos como o parto e o nascimento acabaram por tornar clandestino o trabalho das parteiras tradicionais e expuseram as mulheres quilombolas que buscam os serviços de saúde a violências. No lugar aonde esperava-se encontrar cuidado, essas mulheres encontram violências étnicas e obstétricas ${ }^{4}$.

Por fim, o texto de Longhi nos fala da necessidade de se pensar o Estado como cuidador e questiona a dimensão dos afetos colocada à frente do cuidado com doentes e idosos. A centralidade dos vínculos afetivos idealizados para o cuidado enfraquecem a demanda para que o Estado venha a prover as condições adequadas para tal, de modo a não esgotar as famílias, e dentro delas, as mulheres que são as principais cuidadoras. Vemos, portanto, a dimensão generificada do cuidado em sua relação com o Estado, que atravessa de certa forma todos os artigos.

O atual contexto brasileiro, de desmonte e precarização dos serviços e das políticas públicas, em todas as áreas, mas especialmente na saúde e na educação, e de recrudescimento de visões conservadoras e monolíticas de família, nos impele a enfrentar um Estado que se propõe a ser mínimo, e que com isso maximiza-se de forma deletéria na vida de todos nós que, como seres

\footnotetext{
${ }^{4}$ A violência obstétrica é um problema cujo enfrentamento tem encontrado várias barreiras(CUNHA RODRIGUES et al., 2017). A pesquisa Nascer no Brasil demonstrou que mulheres pretas e pobres são aquelas que sofrerão mais intervenções desnecessárias no parto(LEAL et al., 2017; LEAL; DA GAMA, 2014).
} 
humanos, só existimos graças ao ato do cuidado, que precisa ser partilhado para ser efetivo, justo e duradouro.

\section{REFERÊNCIAS}

ALLEBRANDT, Débora. Sobre mães e doadores Identidade e pertencimento sob a luz da experiência da maternidade, do direito de filiação e acesso à reprodução assistida em uma associação de famílias homoparentais do Quebec Sobre mães e doadores. Civitas, [s. I.], v. 15, n. 2, p. 309-325, 2015.

BESTARD, Joan. Knowing and relating: Kinship, assisted reproductive technologies and the new genetics. In: EDWARDS, Jeanette; SALAZAR, Carles (Eds.). European kinship in the age of biotechnology. [s.l.] : Berghahn Books, 2012. p. 19-44.

CUNHA RODRIGUES, Francisca Alice et al. Violência obstétrica no processo de parturição em maternidades vinculadas à Rede Cegonha. Reproducao e Climaterio, [s. I.], v. 32, n. 2, 2017.

DONZELOT, Jacques. A polícia das famílias. 2. ed. Rio de Janeiro: Graal, 1986.

FINKLER, Kaja. The Kin in the Gene: The Medicalization of Family and Kinship in American. Current Anthropology, [s. I.], v. 42, n. 2, p. 235-263, 2001.

FONSECA, Claudia. De afinidades a coalizões: uma reflexão sobre a "transpolinização" entre gênero e parentesco em décadas recentes da antropologia. Revista Ilha, [s. I.], v. 5, n. 2, p. 05-31, 2003.

. De família, reprodução e parentesco: algumas considerações. Cadernos Pagu, [s. I.], v. d, n. 29, p. 9-35, 2007.

FOUCAULT, Michel. Microfísica do Poder. Rio de Janeiro: Ed. Graal, 2000.

INHORN, Marcia C.; BALEN, Frank Van (EDS.). Infertility around the globe : new thinking on childlessness, gender, and reproductive technologies. Berkeley, Calif. ; London: University of California Press, 2002.

LEAL, Maria do Carmo et al. The color of pain: racial iniquities in prenatal care and childbirth in Brazil. Cadernos de saude publica, [s. I.], v. 33, p. e00078816, 2017.

LEAL, Maria do Carmo; DA GAMA, Silvana Granado Nogueira. Nascer no brasil. Cadernos de Saude Publica, [s. I.], v. 30, n. SUPPL1, p. 2014, 2014.

LEONARD, Lori. Problematizing fertility: "Scientific" accounts and Chadian women's narratives. In: INHORN, Marcia C.; BALEN, Frank Van (Eds.). Infertility around the globe. New thinking on childlessness, gender and reproductive technologies. Los Angeles: University of California Press, 2002. p. 193-213. 
LÉVI-STRAUSS, Claude. As estruturas elementares do parentesco. [s. I.], p. 540, 1982.

MARRE, Diana; BESTARD, Joan. The family body: persons, bodies and resemblance. In: EDWARDS, Jeanette; SALAZAR, Carles (Eds.). European kinship in the age of biotechnology. New York; Oxford: Berghahn Books, 2012. p. 64-78.

MAUSS, Marcel. "A expressão obrigatória dos sentimentos". IN: . Ensaios de sociologia. São Paulo: Editora Perspectiva, 2001, p. 325-335.

MORGAN, Lewis Henry. Systems of consanguinity of the human family. Washington: Smithsonian Institution, 1870.

RIVERS, William Halse. O método genealógico de pesquisa antropológica. In: ROQUE DE BARROS LARAIA (Ed.). Organização social. Rio de Janeiro: Zahar Editores, 1969. p. 26-38.

SCHNEIDER, David Murray. A critique of the study of kinship. Michigan: University of Michigan Press, 1984.

SILVERMAN, Chloe. Brains, pedigrees and promisses: lessons from the politics of autism genetics. In: GIBBON, Sahra; NOVAS, Carlos (Eds.). Biosocialities, genetics and the social sciences. London; New York: Routledge, 2008. p. 38-55. 